\title{
Einsparung der Gesundheitskosten: Wer übernimmt Verantwortung? Wer wird belohnt, wer bestraft?
}

\section{J. Berner}

Korrespondenz: Dr. med. Jean Berner Bahnhofstrasse 48 CH-8305 Dietlikon
Letztlich vor meiner Praxis geschehen: Ein Gast des nahegelegenen Restaurants fällt und zieht sich eine kleine Wunde der Augenbraue zu. Trotz des Protestes des Betroffenen wird die Sanität gerufen, die ihn ins Spital mitnehmen will: erneut Weigerung des Patienten. Die Polizei wird gerufen, will ihn mit dem Polizeiwagen ins Spital bringen: Weigerung. Meine Arztgehilfin stösst zufällig dazu, bietet eine kleine Wundversorgung in meiner Praxis an: Weigerung. Der Wirt will keine Verantwortung übernehmen und ruft erneut die Sanität, diesmal mit Notarzt. Der Kollege versorgt den Patienten am Wirtshaustisch, der Patient genehmigt sich anschliessend noch einen Trostschluck und schwankt heimwärts. Kosten: etwa Fr. 2000.--

Ich versuche, die Szene vor 50 Jahren zu rekonstruieren: Ein Gast des nahegelegenen Restaurants fällt und zieht sich eine kleine Wunde der Augenbraue zu. Die Serviertochter ruft den Wirt, holt ein Tuch und etwas Eis aus dem Kühlschrank, macht einen kalten Umschlag, bis es zu bluten aufhört. Der Wirt kommt mit einem Streifen Heftpflaster, klebt die Wunde irgendwie zusammen, und schlägt dem Gast vor, doch noch schnell beim nahegelegenen Arzt reinzuschauen. Als sich dieser weigert, weigert sich der Wirt seinerseits, dem Mann einen Trostschluck $\mathrm{zu}$ kredenzen und entlässt ihn in Begleitung eines andern Gastes, der in der gleichen Richtung wohnt. Kosten: null Franken. Die Lehren:
1. Viele Menschen haben Angst, etwas falsch zu machen, handeln nicht und fordern professionelle Hilfe an.

2. Auch professionelle Helfer unterlassen es oft, eine telephonische Triage $\mathrm{zu}$ machen, was zu Fehleinsätzen führt, die Überkapazitäten dieser Organismen nach sich zieht. Professionelle Helfer sind deshalb teurer als die Grundversorger.

3. Professionelle Hilfe wird nicht nur häufiger angefordert, sondern in der Einzelleistung immer teurer. Ein Restrisiko für einen Verunfallten lässt sich aber auch mit extremen Kosten nicht eliminieren.

4. Notfalldienst ist Service public. Der freie Wettbewerb kann im Notfalldienst nicht spielen, da die Deregulierung der Notfallversorgung wegen ihrer Unregelmässigkeit noch mehr Überkapazitäten generieren würde.

5. In der Schweiz wird niemand wegen Verursachung von Kosten belangt, für Einsparungen belohnt. Genau dies müsste jedoch geschehen, und zwar bei allen Akteuren, so da sind: Versicherte, Angehörige, Ärzteschaft, Rettungswesen, Spitäler, Krankenkassen, Versicherungen und Politiker. Statt dessen werden punktuelle, neue Ungerechtigkeiten schaffende Massnahmen getroffen, die die ehrlich und integer Arbeitenden bestraft, so der Zulassungsstopp. 